2011-06-30

\title{
A novel methodology for evaluating user interfaces in health care
}

\author{
Luca Longo \\ Technological University Dublin, luca.longo@tudublin.ie \\ Bridget Kane \\ Trinity College Dublin, Ireland
}

Follow this and additional works at: https://arrow.tudublin.ie/scschcomcon

Part of the Artificial Intelligence and Robotics Commons

\section{Recommended Citation}

L. Longo and B. Kane, "A novel methodology for evaluating user interfaces in health care," 2011 24th International Symposium on Computer-Based Medical Systems (CBMS), 2011, pp. 1-6, doi: 10.1109/ CBMS.2011.5999024.

This Conference Paper is brought to you for free and open access by the School of Computer Sciences at ARROW@TU Dublin. It has been accepted for inclusion in Conference papers by an authorized administrator of ARROW@TU Dublin. For more information, please contact arrow.admin@tudublin.ie, aisling.coyne@tudublin.ie,gerard.connolly@tudublin.ie.

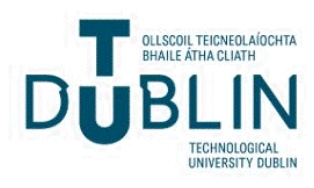




\title{
A Novel Methodology for Evaluating User Interfaces in Health Care
}

\author{
Luca Longo and Bridget Kane* \\ Department of Computer Science and Statistics \\ Trinity College Dublin \\ \{llongo, kanebt\}@scss.tcd.ie
}

\begin{abstract}
A pilot study is reported to identify an improved method of evaluating digital user interfaces in health care. Experience and developments from the aviation industry and the NASA-TLX mental workload assessment tools are applied in conjunction with Nielsen heuristics for evaluating an Electronic Health Record System in an Irish hospital. The NASA-TLX performs subjective workload assessments on operators working with various human-computer systems. Results suggest that depending on the cognitive workload and the working context of users, the usability will differ for the same digital interface. We conclude that incorporating the NASA-TLX with Nielsen's heuristics offers a more reliable method in design and evaluation of digital user interfaces in clinical environments, since the healthcare work context is taken into account. Improved interfaces can be expected to reduce medical errors and improve patient care.
\end{abstract}

\section{Introduction}

In health care, the use of Electronic Health Record (EHR) Systems are slowly replacing traditional paper-based patients records. This transition from paper-based to digitalbased systems has been leading users to use digital interfaces. As a consequence, the evaluation of user interfaces is an increasingly important research field devoted to enhance systems' usability [9]. Nielsen's principles represent the most adopted heuristic to test the usability of an interface due to their simplicity in terms of effort and time. The evaluation is done by systematically finding usability problems in an interface and judging them according to the usability principles in an iterative design process. However, the heuristics mainly focus on the user interface without considering external factors such as the environment context of use and the cognitive state of its users. In health care environments, clinicians, nurses, doctors and other operators are often forced to work under pressure, with patients

${ }^{*}$ IRCSET Research Fellow whose dependency score can be relative high. Therefore, the cognitive state of these workers is constant flux, often influenced by periods of stress and pressure punctuated by more calm and relaxing time intervals. For a clinician using an interface, his/her experience and judgement is likely influenced by his/her environment and mental state. We are interested in assessing a clinician's cognitive state while using a certain interface that might affect their experience and evaluation of it. For this reason, we have adopted the NASA-TLX methodology [3], mainly applied in the aviation sector, to generate indexes of the mental workload of a person after the execution of a task. We report a pilot study in an Irish hospital evaluating the usability of an EHR used by two clinicians, independently in different wards, occupied by patients with high dependency scores. A questionnaire that incorporates Nielsen's principles and the NASATLX, was completed by clinician volunteers after each use of the EHR. Results were correlated to examine the impact of the mental state of a person on the usability of the EHR. State-of-the-art: Nielsen's 10 usability principles, "heuristics", can successfully identify the vast majority of the usability problems of a system [9]. This subjective tool has been used in different contexts and has recently been adopted in health information studies to test the usability of web-based EHRs, medical equipment, web design, Internet health tools and services [10]. The evaluation and design of software, for health-care information systems, involves the deployment of the system development life cycle methodology (SDLC) in health informatics [7]. Usability has been shown as a major factor in both acceptance [8] and effectiveness [6] of EHR systems in clinical settings. Usability evaluations are often carried out by administering questionnaires to users who provide explicit feedback. Their opinions are subjective and may be influenced by their cognitive state while answering questions. A busy or tired person may experience an interface being difficult to use, compared to another who is less frustrated, relaxed and attentive. It is intuitive that human factors play an important role and should be considered when evaluating user interfaces. Indeed, it is 


\begin{tabular}{|c|c|c|c|c|}
\hline Label & Question & Tested issue & Scale & Impact on US \\
\hline$N Q_{1}$ & $\begin{array}{l}\text { "Does the system always keep you informed about what is going on } \\
\text { through appropriate feedback within reasonable time?" }\end{array}$ & Feedback & low/high & Positive/Negative \\
\hline$N Q_{2}$ & $\begin{array}{l}\text { "Does the system speak the users' language, with words, phrases and } \\
\text { concepts familiar to the user, rather than system-oriented terms?" }\end{array}$ & $\begin{array}{l}\text { Speak Users' } \\
\text { Language }\end{array}$ & low/high & Positive/Negative \\
\hline$N Q_{3}$ & $\begin{array}{l}\text { "Does the system support undo and redo functionalities to leave the } \\
\text { unwanted state without having to go through an extended dialogue?" }\end{array}$ & $\begin{array}{l}\text { Clearly Marked } \\
\text { Exits }\end{array}$ & low/high & Positive/Negative \\
\hline$N Q_{4}$ & $\begin{array}{l}\text { "Does the users have to wonder whether different words, } \\
\text { situations, or actions mean the same thing?" }\end{array}$ & Consistency & low/high & Negative/Positive \\
\hline$N Q_{5}$ & "Does the system present lots of error messages?" & $\begin{array}{l}\text { Prevent } \\
\text { Errors }\end{array}$ & low/high & Negative/Positive \\
\hline$N Q_{6}$ & $\begin{array}{l}\text { "Does the system minimize the user's memory load by making objects, } \\
\text { actions, and options visible?" }\end{array}$ & $\begin{array}{l}\text { Minimize Use } \\
\text { Memory Load }\end{array}$ & low/high & Positive/Negative \\
\hline$N Q_{7}$ & $\begin{array}{l}\text { "Does the system provide shortcuts to jump quickly to a certain } \\
\text { functionality accelerating the interaction with frequent actions?" }\end{array}$ & Shortcuts & low/high & Positive/Negative \\
\hline$N Q_{8}$ & $\begin{array}{l}\text { "Does the system show dialogues that contain information } \\
\text { which is irrelevant or rarely needed?" }\end{array}$ & $\begin{array}{l}\text { Simple/Natural } \\
\text { Dialogue }\end{array}$ & low/high & Negative/Positive \\
\hline$N Q_{9}$ & $\begin{array}{l}\text { "Does the system present error messages expressed in plain language } \\
\text { precisely indicating the problem, constructively suggesting a solution?" }\end{array}$ & $\begin{array}{l}\text { Good Error } \\
\text { Messages }\end{array}$ & low/high & Positive/Negative \\
\hline$N Q_{10}$ & $\begin{array}{l}\text { "Does the system provide help/documentation easy to search, focused on } \\
\text { the user's task, list concrete steps to be carried out, and not be too large?" }\end{array}$ & $\begin{array}{l}\text { Help and } \\
\text { Documentation }\end{array}$ & low/high & Positive/Negative \\
\hline
\end{tabular}

Table 1: Nielsen-based questionnaire

argued that assessments of performance should be taken into consideration in evaluations [1]. The design of optimal and functional EHR systems and interfaces is important because they can significantly impact patient care [12]. NASA aerospace developed the NASA Task Load Index (NASATLX) to test the workload of pilots and its effects in their work [3], to assess the human mental workload of users while executing a task. Widely used in aeronautics and aviation, where it is mainly adopted for studying the impact of distraction of drivers in vehicle control [4], it is slowly moving into the health sector. The NASA-TLX was used to reduce the surgical workload in single-incision laparoscopy, by using it in simulation labs to help students acquire the skill necessary for suturing [11], and to assess the subjective workload of clinicians in perianesthesia nursing [13].

\section{Methodology and Experiment Design}

This pilot study was conducted in an Irish hospital which cares for an elderly population. Two wards were chosen: Ward A has 18 patients, and Ward B has 10 patients. Ward A patients typically have higher dependency scores than those in Ward B, because Ward A patients are long stay elderly people. Patients in Ward B are short-term stay individuals who are intermittently admitted to hospital for respite. The two wards demand different levels of physical and mental stress for staff but both use the same EHR system to document each patient's daily progress.

EHR task: The EHR's user interface has a structured design with several questions and tick boxes aimed at helping clinicians to have an overview of the day-to-day life of a patient. The system allows assessment of a patient's state of health through questions on various aspects such as mental state, continence, nutrition, hydration, mood, pain, mobility, skin condition, safety, sleep, rest and spiritual needs. The number of questions, for each section, varies from 2 to a maximum of 14 and clinicians answer these several times within their 12 hours working day. For our experiment we formally define, in Table 2 , the task that the two clinicians, responsible of the selected wards, one each, needed to perform over the EHR interfaces:

TASK: "answering EHR questions about patients' health state"

Evaluation Tool The first part of the questionnaire was designed to meet the usability principles proposed by Nielsen [9]: the questions, in Table 1, test the usability and effectiveness of the EHR system for its design and how clinicians experience it's use in their busy schedule. For questions 1, 2, 3, 6, 7, 9, 10, a high score means that the designed functionality has a positive impact on usability. A low score suggests there is a design problem in the system. For questions $4,5,8$, instead, a high value prompts a design problem while a low score underlines a well implemented functionality. The second pool of questions represent the NASA-TLX questionnaire [3] to assess the mental workload of a user and are presented in Table 2. The Performance factor scale, in the original NASA-TLX questionnaire [3], varies from good to poor: decrements in performance correspond to increments in the final mental workload. In our experiment design, we have reversed the scale to be in line with the other 5 questions, in order to minimise confusion of users. This change is taken into account in the formal computation of the final HMW scores, converting back to the performance score of the original NASA-TLX scale.

The research question in this study is: To what extent do human factors influence the usability of a digital interface? Practically, answering this question means answering: To what extent does the human mental workload, imposed by the adopted EHR system, influence its usability? 


\begin{tabular}{|c|c|c|c|c|}
\hline Label & Question & Area & Scale & Impact on HMW \\
\hline$N T Q_{1}$ & $\begin{array}{l}\text { "How much mental and perceptual activity was required (e.g. thinking, } \\
\text { deciding, calculating, remembering, looking, searching, etc.)? Was the } \\
\text { task easy or demanding, simple or complex, exacting or forgiving?" }\end{array}$ & $\begin{array}{l}\text { Mental } \\
\text { Demand }\end{array}$ & low/high & Positive/Negative \\
\hline$N T Q_{2}$ & $\begin{array}{l}\text { "How much physical activity was required (e.g. pushing, pulling, } \\
\text { turning, controlling, activating, etc.)? Was the task easy or } \\
\text { demanding, slow or brisk, slack or strenuous, restful or laborious?" }\end{array}$ & $\begin{array}{l}\text { Physical } \\
\text { Demand }\end{array}$ & low/high & Positive/Negative \\
\hline$N T Q_{3}$ & $\begin{array}{l}\text { "How much time pressure did you feel due to the rate or pace at which } \\
\text { the tasks or task elements occurred? } \\
\text { Was the pace slow and leisurely or rapid and frantic?" }\end{array}$ & $\begin{array}{l}\text { Temporal } \\
\text { Demand }\end{array}$ & low/high & Positive/Negative \\
\hline$N T Q_{4}$ & $\begin{array}{l}\text { "How hard did you have to work (mentally and physically) } \\
\text { to accomplish your level of performance?" }\end{array}$ & Effort & low/high & Positive/Negative \\
\hline$N T Q_{5}$ & $\begin{array}{l}\text { "How successful do you think you were in accomplishing the goals, } \\
\text { of the task set by the experimenter (or yourself)? How satisfied were } \\
\text { you with your performance in accomplishing these goals? }\end{array}$ & Performance & poor/good & Negative/Positive \\
\hline$N T Q_{6}$ & $\begin{array}{l}\text { "How insecure, discouraged, irritated, stressed and annoyed versus secure, } \\
\text { gratified, content, relaxed and complacent did you feel during the task?" }\end{array}$ & Frustration & low/high & Positive/Negative \\
\hline
\end{tabular}

Table 2: NASA-TLX questionnaire

We correlate the first set of questions (Nielsen principles) with the second set (NASA-TLX). The former subjectively tests the usability of the EHR's interfaces while the latter assesses the mental workload of the clinicians imposed by the EHR's interfaces. Formally, the 10 questions of Table 1 (NQs) are mathematically averaged to produce a final usability value $U S$ (questions $4,5,8$ have the inverted scale):

$$
\begin{gathered}
N Q_{i}:[1 . .10] \in \aleph, \quad 1 \leq i \leq 10, \quad U S:[0 . .1] \in \Re \\
U S=\left(\sum_{i=\{1|2| 3|6| 7|9| 10\}} N Q_{i}+\sum_{i=\{4|5| 8\}}\left(10-N Q_{i}\right)\right) \frac{1}{10}
\end{gathered}
$$

The NASA-TLX model is not based on a simple average of the 6 questions of Table 2 (NTQs), rather on a weighted aggregation. These questions are formally expressed as:

$$
N T Q_{x}:[0 . .1] \in \aleph, \quad x:\{M|P D| T|E| P \mid F\}
$$

The weight of each of the 6 considered areas needs to be computed. Clinicians needed to decide, for each possible pair of the 6 areas (binomial coefficient), 'which of the two contributed more to their workload during the task', such as 'Mental or Physical Demand?', 'Physical Demand or Performance?', and so forth, giving a total of 15 preferences.

$$
\left(\begin{array}{l}
6 \\
2
\end{array}\right)=\frac{6 !}{2 !(6-2) !}=15
$$

The weights are the number of preferences, for each area, in the 15 answer set. In other words, the number of times that each factor was selected. The range is from 0 (not relevant) to 5 (more important than any other factor). Formally:

$$
N T W_{x}:[0 . .5] \in \aleph, \quad x:\{M|P D| T|E| P \mid F\}
$$

The final human mental workload score (HMW) of users is computed by multiplying the score of each NTQ question by its computed weight NTW (Note the Performance value is brought back to the original NASA-TLX scale):

$$
\begin{gathered}
H M W:[0 . .1] \in \Re, \quad x:\{M|P D| T|E| P \mid F\} \\
H M W=\left(\sum_{x=\left\{\begin{array}{l}
M|P D| \\
T|E| F
\end{array}\right.} N T Q_{x} \cdot N T W_{x}+\sum_{x=\{P\}}\left(10-N T Q_{x}\right) \cdot N T W_{x}\right) \frac{1}{15}
\end{gathered}
$$

\section{Results}

The parameters of the experiments are shown in Table 3. The questionnaires of Table 1 and 2 have been answered immediately after executing the task described in Section 2. This means that 180 questions, in the first experiment (Exp. 1), and 140 in the second experiment (Exp.2), were answered, to test the usability (NQ questions), and to test the imposed mental workloads (NTQ questions) by the EHR system. For the computation of the NASA-TLX 6 areas' weights, the users always show the same preferences (the pairwise comparisons), generating the weights in Table 4, because the EHR TASK does not change over time.

\begin{tabular}{|l|c|c|c|c|}
\hline Exp. No. & Patients N. & Days & Ward & Clinician \\
\hline Exp. 1 & 18 & 5 & A & A \\
\hline Exp. 2 & 10 & 7 & B & B \\
\hline
\end{tabular}

Table 3: Experiments description

\begin{tabular}{|l|l|c|}
\hline Weight label & NASA-TLX Area & Preference \\
\hline$N T W_{M}$ & Mental demand & 3 \\
$N T W_{P H}$ & Physical demand & 0 \\
$N T W_{T}$ & Temporal & 2 \\
$N T W_{P}$ & Performance & 4 \\
$N T W_{E}$ & Effort & 1 \\
$N T W_{F}$ & Frustration & 5 \\
\hline
\end{tabular}

Table 4: Pair-Wise NASA-TLX sub-scale comparisons

Experiment 1 results Figure 1 shows results of experiment 1 (Exp. 1). Subfigure (a) describes how the clinician, evaluator of the EHR's user interface usability, has answered the questionnaire of Table 1 (NQs). Results are grouped by patient. Users' answers, after each completion of the EHR TASK (Section 2), are grouped together in a boxplot containing the results for the whole period (5 days). For questions 1, 4, 5, 7, 8, 9 of Table 1, the flat line shows that the subjective answers do not vary over patients, having a null impact, while questions $2,3,6,10$ of Table 1, vary, even though over a restricted range, having a minor impact. The last score of subfigure (a), the computed usability value $(U S)$, does not significantly decrease 


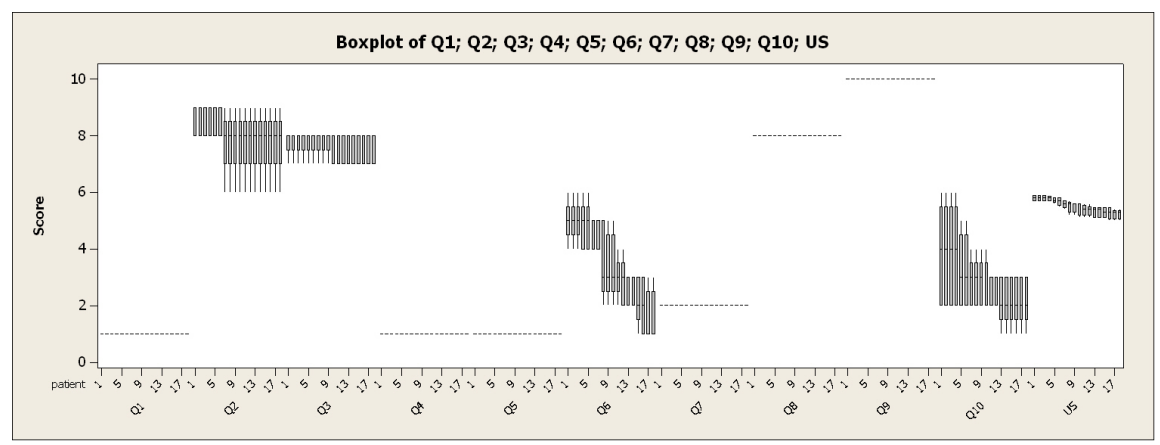

(a) Boxplot of scores: Nielsen-based usability questions (NQs)

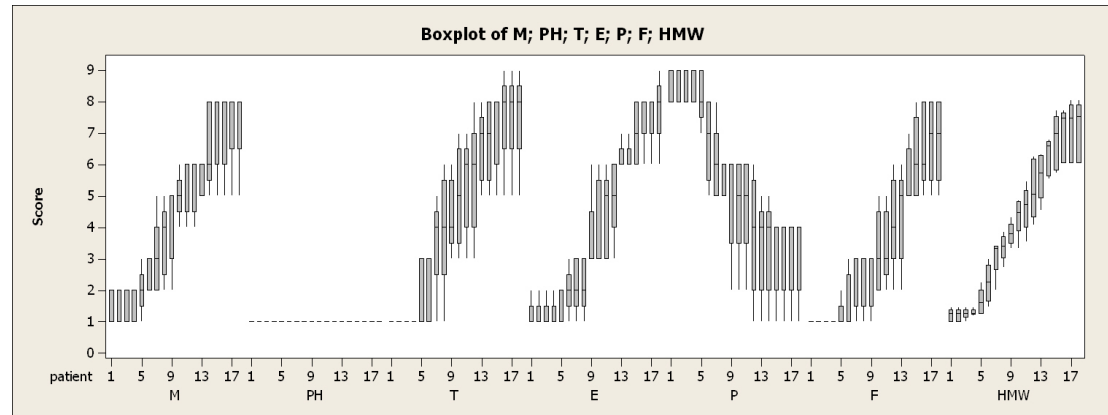

(b) Boxplot of scores: the NASA-TLX questionnaire (NTQs)

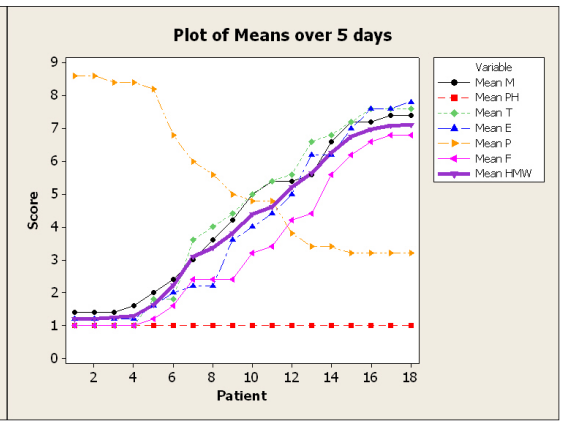

(c) NASA-TLX areas and HMW scores

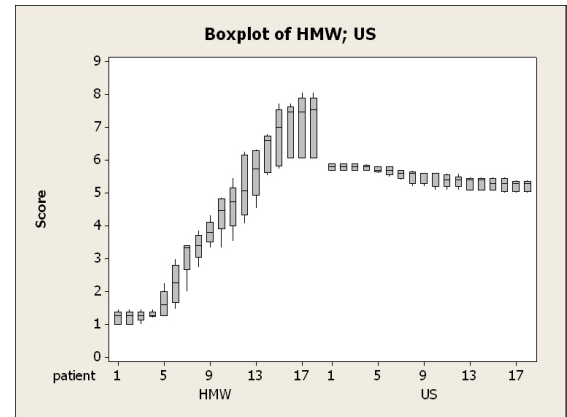

(d) Boxplot US scores vs HMW scores

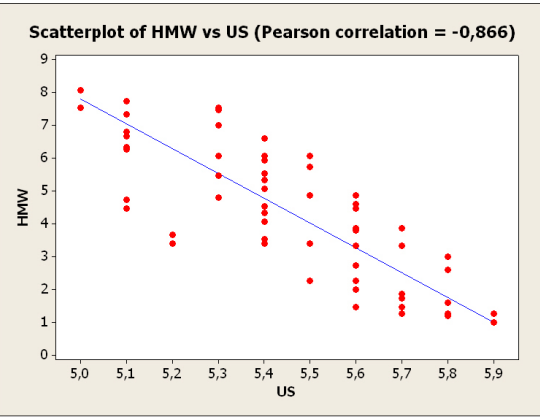

(e) Scatterplot US scores vs HMW scores

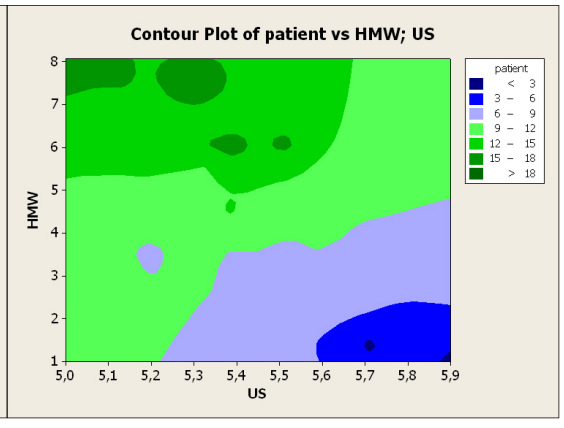

(f) Contour plot US scores vs HMW scores

Figure 1: Experiment 1 - 18 patients, 5 days, clinician no. 1

over patients: the usability of the EHR's interfaces slowly decreases. The subfigures $(b, c)$ of Figure 1 describe the answers of the NASA-TLX questionnaire (NTQ questions) of Table 2. The Mental Effort significantly increases over time, after each completion of the EHR TASK (Section 2). The same happens for the Temporal Demand, Effort and Frustration, while the clinician's performance significantly decreases over time. The Physical Demand is stable and null, as the EHR TASK involves mainly cognitive modalities rather than physical channels. The computed indexes of Human Mental Workload (HMW scores) increase after the completion of the EHR TASK: the clinician needs to put more cognitive effort into its execution. The subfigures (d, e, f) of Figure 1 describe the correlation between the computed usability scores $(U S)$ and the mental workload required by the EHR interface on clinicians for executing the EHR TASK (Section 2). Evident increments of human mental workloads $(H M W)$ correspond to moderate decrements in the level of usability $(U S)$. The EHR's interfaces are experienced being less usable when mental workload is high, supported by a distinct correlation of $r=-0.866$. The contour plot (subfigure f), instead, better describes how users' answers change as a function of usability $(U S)$ and mental workload $(H M W)$. At the beginning of the clinician working day, the usability is high, with low mental workloads, while at the end of the day, the usability decreases with increments in the workload levels.

Experiment 2 results Figure 2 shows results of experiment 2 (Exp. 2). Subfigure (a) describes clinician's answers of the usability questionnaire of Table 1 (NQs). Scores are grouped by patient. Users' answers, after execution of the EHR TASK (Section 2), are grouped together forming a boxplot drawn over the entire experiment period (7 days). For questions 5, 7 the subjective answers do not 


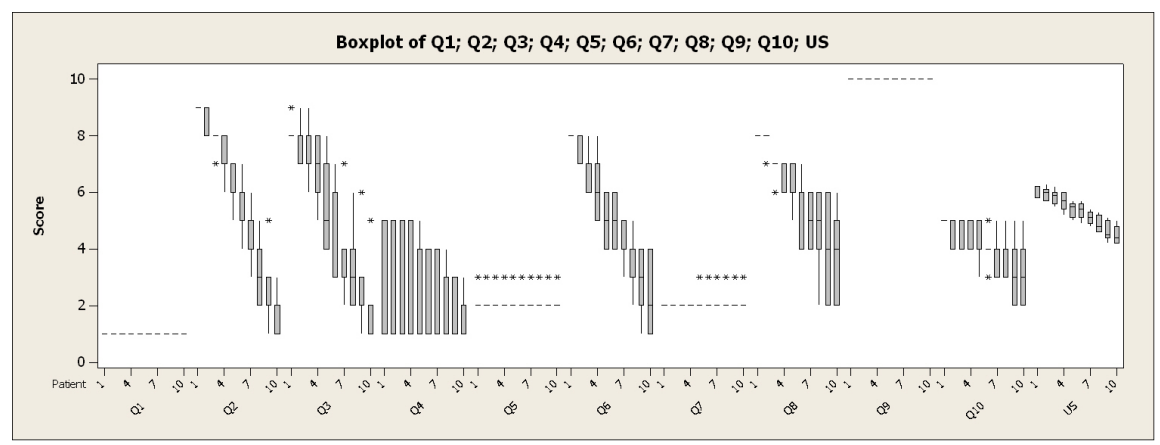

(a) Boxplot of scores: Nielsen-based usability questions (NQs)

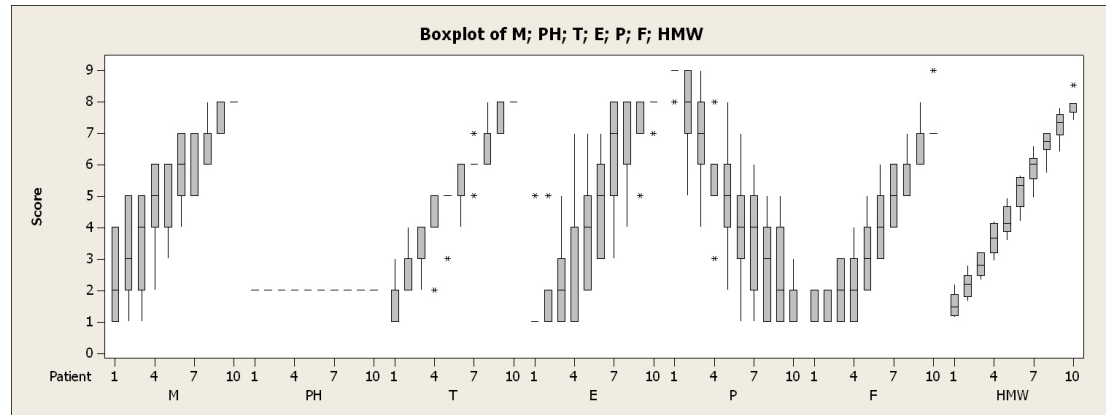

(b) Boxplot of scores: the NASA-TLX questionnaire (NTQs)

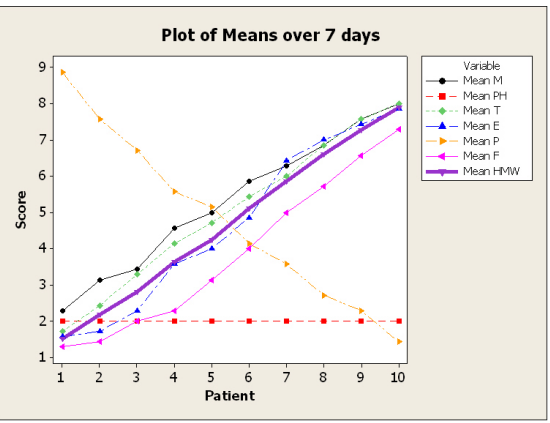

(c) NASA-TLX areas and HMW scores

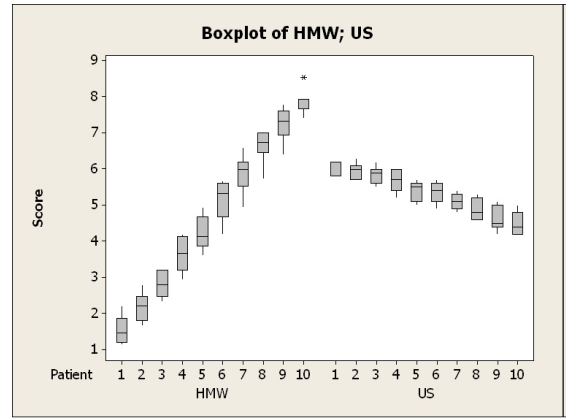

(d) Boxplot US scores vs HMW scores

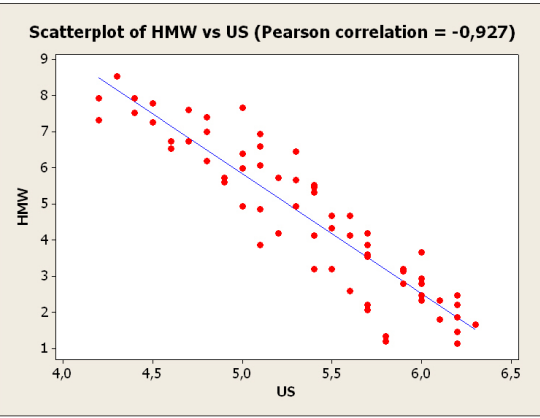

(e) Scatterplot US scores vs HMW scores

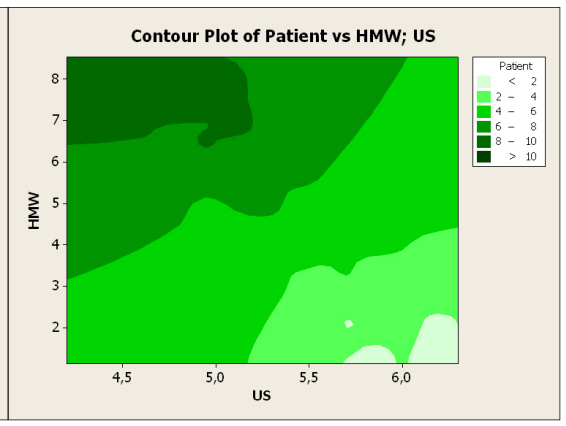

(f) Contour plot US scores vs HMW scores

Figure 2: Experiment 2 - 10 patients, 7 days, clinician no. 2

vary significantly, underlying minor impact over EHR usability. For questions 1 and 9, scores do not vary at all over patients, thus there is no usability impact. Answers to questions $2,3,4,6,8$ show a higher variance, underlying the decrement of the usability for that particular design issue. Like experiment 1 (Exp.1), the computed usability scores $(U S)$ decrease slowly: the clinician experiences the EHR having more design problems over time (over patients).

The subfigures $(b, c)$ of Figure 2 describe the answers of the NASA-TLX questionnaire (NTQ questions) of Table 2. The graphs look exactly the same as experiment 1 (Exp.1), with the factors, except the Physycal Demand, having a great variance. The Mental Effort, the Temporal Demand, the Effort and Frustration increase over time, after each execution of the EHR TASK (Section 2), while the clinician's performance significantly decreases. The Physical Demand is stable and null, as the EHR TASK is mainly a cognitive task rather than physical. The indexes of Human Mental Workload (HMW computed scores) increase moderately, but permanently, after each completion of the EHR TASK: the clinician's cognitive effort is constantly and increasingly demanded by the EHR system. The subfigures (d, e, f) of Figure 2 show how the computed usability score and the mental workload required by the EHR TASK (Section 2) are correlated. Increments of human mental workload levels $(H M W)$ correlate to mediocre decrements of usability scores $(U S)$. The usability and the experience of the EHR's interfaces are lower when mental workload is high, supported by a significant correlation of $r=-0.927$. The contour plot (subfigures f) emphasises how user's scores over patients (over time) change as a function of usability (US) and workload $(H M W)$. At the start of the day, when the EHR TASK (Section 2) is performed for the first time by the clinician, the usability is high and there is low mental 
workload. At the end of the 12-hours working day, after multiple execution of the EHR TASK (Section 2), the usability decreases with increments in the workload levels.

General Interpretations Boxplots 1 (a) and 2 (a) suggest that the usability of the EHR can vary over time, even though the interface is the same. This is supported by the results of boxplots b, $c$ of Figures 1 and 2 for both the experiments. As clinicians approach the end of their working day, their performance in accomplishing their task on the EHR system drastically decreases. As a result, they need to pay more attention to reach the same level of performance on the same task, eliciting more mental workload. The correlation between usability $(U S)$ and mental workload $(H M W),(\mathrm{d}$, $\mathrm{e}, \mathrm{f}$ of Figures 1 and 2 ) required by the EHR TASK (Section 2), is significant. This suggests that the design process of an EHR's should take greater account of the context of use and the mental workload of its clinical users.

\section{Conclusion and Future Work}

Nielsen principles [9] represent the most adopted paradigm for evaluating the usability of digital interfaces. However, they consider a set of functionalities an interface should conform to, without fully considering the context of system use and the impact that a user's workload may have on their use of the system. This study prompts consideration of human factors in the evaluation process of a user interface in health care. The concept of human mental workload is envisaged, a complex construct that accounts for parameters such as mental, physical and temporal demands, performance, effort and frustration of a user while executing a task. The evidence gathered through the questionnaire that incorporates Nielsen's principles and NASA-TLX, suggests that the mental workload of the clinician demanded by the EHR's interface increases over time, after repetitive use. As mental workload increases, there is a negative correlation with the usability of the system. This is explained by the environmental constraints of a typical health care setting where clinicians are exposed to increasing stress and frustration, with losses of performance over the typical working day. With the reduction of attention and an increment in mental workload levels, the clinicians experienced the EHR differently, being more difficult and non-usable after multiple uses. The experiment outcomes are encouraging and suggest that further studies and tests should be conducted. More reliable methods to evaluate digital user interfaces need to be developed for application in health care environments. The clinical usability of EHR systems is extremely important because it affects patient care. Therefore technologies should help improve clinical care and not impose unnecessary mental workload on clinical staff.

Acknowledgements Thanks to R. T. Venkateshappa, R. Ravikuma and K. Nagesh for helping in gathering data. B. Kane is funded through the IRCSET Enterprise Partnership scheme with St. James's Hospital Board, Dublin.

\section{References}

[1] Beyan O.D., Baykal N., A Knowledge Based Search Tool for Performance Measures in Health Care Systems. Journal of Medical Systems, 2010 [Forthcoming]

[2] Desurvire H. W., Faster, Cheaper!! Are Usability Inspection Methods as Effective as Empirical Testing? Usability Inspection Methods, 1994, pp. 173-202.

[3] Hart S., Staveland L., Development of Nasa-TLX (task load index): Results of Empirical and Theoretical Research. Human Mental Workload, 1988, pp. 139-183.

[4] Harbluk J. L., Noy Y., The Impact of Cognitive Distraction on Driver Visual Behaviour and Vehicle Control. Transportation Canada.

[5] Jeffries R., Miller J.R., Wharton C., Uyeda K.M., User Interface Evaluation in The Real World: A Comparison of Four Techniques. Proc. CHI Conf., 1991 p.119-124.

[6] Koppel R., Metlay JP., Cohen A., et al., Role of Computerized Physician Order Entry Systems in Facilitating Medication Errors. JAMA, 2005, 293(10) pp. 1197-203.

[7] Kushniruk A., Evaluation in The Design of Health Information System: Application of Approaches Emerging from Usability Engineering. Computers in biology and Medicine, 2002, V. 32, pp. 141-149.

[8] Linder J.A., Schnipper J.L., Tsurikova R., et al., Barriers to Electronic Health Record Use During Patient Visits. Proc. of AMIA Annu Symp. 2006, pp. 499-503.

[9] Nielsen J., Heuristic evaluation. Usability Inspection Methods, 1994, John Wiley \& Sons, New York, NY.

[10] Nahm E.S., Preece J., Resnick B., Mills ME., Usability of Health Web Sites for Older Adults: a Preliminary Study. Computers, Informatics, Nursing, 2004, V. 22(6), pp. 326-34.

[11] Rieder E., Martinec V.M., Casserea M., Trudie, A triangulation Operating Platform Anhances Bimanual Performance and Reduces Surgical Workload in Singleincision Laparoscopy. Journal of American college of Surgeons, 2011, V. 212-3, pp. 378-384.

[12] Walsh S.H., The Clinician's Perspective on Electronic Health Records and How They Can Affect Patient Care. BMJ Medical Journal. 2004, 328(7449), pp. 1184-7.

[13] Young G., Zavelina L., Hooper V., Assessment of Workload Using NASA Task Load Index in Perianesthesia Nursing. Journal of Perianesthesia Nursing, V. 23-2, 2008, pp. 102-110. 